\title{
Perfis Epistemológicos dos Livros Didáticos de Física do PNLD de 2018
}

\author{
Renata da Silva Trintin \\ Luciano Carvalhais Gomes
}

\begin{abstract}
RESUMO
Neste artigo, apresentamos parte dos resultados da dissertação da primeira autora. A pesquisa teve por objetivo analisar alguns livros didáticos de Física avaliados pelo Plano Nacional do Livro Didático (PNLD) de 2018, com relação aos perfis epistemológicos de Bachelard sobre o conceito de força. Dentre os livros selecionados do PNLD, escolhemos seis que fazem parte da coleção da biblioteca do Colégio de Aplicação Pedagógica da Universidade Estadual de Maringá (CAP-UEM). A metodologia de análise foi feita seguindo as três etapas da análise de conteúdo propostas por Bardin (1997). As categorias foram identificadas a priori baseadas nos perfis elencados por Bachelard (1978). Verificamos que os livros estão sobrecarregados de imagens e trechos que refletem o perfil Realista. Também há uma quantidade expressiva do perfil Racionalista Clássico.
\end{abstract}

Palavras-chave: Ensino de Física. Força. Livro Didático. Perfil Epistemológico.

\section{Epistemological Profiles of the 2018 PNLD Physics Didactic Books}

\begin{abstract}
In this article, we present part of the results of the dissertation of the first author. The research had as objective to analyze some textbooks of Physics evaluated by the National Plan of the Didactic Book (PNLD in portuguese) of 2018 with respect to the epistemological profiles of Bachelard on the concept of force. Among the selected PNLD books, we chose six that are part of the library collection of the College of Pedagogical Application of the State University of Maringá (CAP-UEM in portuguese). The methodology of analysis was made following the three stages of the content analysis proposed by Bardin (1997). The categories were identified a priori based on the profiles listed by Bachelard (1978). We find that books are overloaded with images and snippets that reflect the Realistic profile. There is also an expressive amount of the Classic Rationalist profile.
\end{abstract}

Keywords: Physics Teaching. Force. Didactic Book. Epistemological Profile.

\section{INTRODUÇÃO}

De acordo com Bachelard (1978), há diferentes formas de pensar sobre um conceito e cada uma delas pode ser entendida como sendo um perfil epistemológico. Quando

\footnotetext{
Renata da Silva Trintin é graduada em Licenciatura em Física. Atualmente é mestranda no Programa de Pós-graduação em Educação para a Ciência e a Matemática (PCM) na Universidade Estadual de Maringá (UEM) - Campus Maringá. Endereço: Avenida das Grevíleas, 421 - Maringá, PR. CEP: 87025-310. Email: renatatrintin@gmail.com

Luciano Carvalhais Gomes é Doutor em Educação para a Ciência e a Matemática pela Universidade Estadual de Maringá (2012). Atualmente, é Professor Adjunto C do Departamento de Física e do Programa de Pós-Graduação em Educação para a Ciência e a Matemática (PCM) da Universidade Estadual de Maringá (UEM) - Campus Maringá. Email: Icgomes2@uem.br

Recebido para publicação em 23 jan. 2018. Aceito, após revisão, em 22 mar. 2018.
} 
exemplificou o seu perfil epistemológico do conceito massa e posteriormente do conceito de energia, o autor criou uma escala graduada para ilustrar esses perfis, semelhante a um gráfico de barras. Essa escala se organiza de maneira hierárquica, contemplando as cinco filosofias que embasam cada perfil. A seguir, temos o exemplo para o conceito de massa: a) realismo ingênuo: refere-se à primeira visão ou sensação obtida do objeto, sem criticidade. É o pensamento de senso comum. O realista só atribui massa àquilo que é pesado, e/ou ele acredita que quanto maior for o objeto, mais massa terá; b) empirismo claro e positivista: refere-se às experiências com base na manipulação do objeto, essa é capaz de ultrapassar a realidade imediata do realista. Há a coleta de dados por meio de instrumentos, como uma balança de pratos, para concluir qual objeto possui mais massa, sem o emprego do racionalismo; c) racionalismo clássico: o conceito se constrói por meio da racionalização, não se tem apenas a experiência simplista e imediata. Compreende ainda, dependendo do conceito, a racionalização matemática, assim como a massa newtoniana que é a razão da força pela aceleração; d) racionalismo completo (ou complexo): Aumenta-se o grau de abstração com o aprimoramento da matematização adquirida com a ciência contemporânea. Ultrapassa o racionalismo clássico quando rompe com a superfície das noções e aprofunda em seu interior para alcançar um conceito, como a massa einsteiniana que é variável e está relacionada à energia; e) racionalismo discursivo (ou dialético): É o racionalismo probabilístico, como o conceito de "massa negativa" de Dirac. Esse racionalismo discursivo ultrapassa as outras filosofias com um pensamento além do racional, o ultrarracional. Há a necessidade da dialética do racionalismo com o empirismo.

A Figura 1 apresenta um esquema sobre o perfil epistemológico que Bachelard construiu para o seu conceito de massa. Nas abscissas, estão as filosofias em ordem crescente de complexidade racional, da esquerda para a direita. Nas ordenadas, as alturas das barras compreendem, grosseiramente, a quantificação da utilização da noção, indicando a importância relativa que ela tem para o seu proprietário. O perfil, portanto, constitui-se como do sujeito, individual.

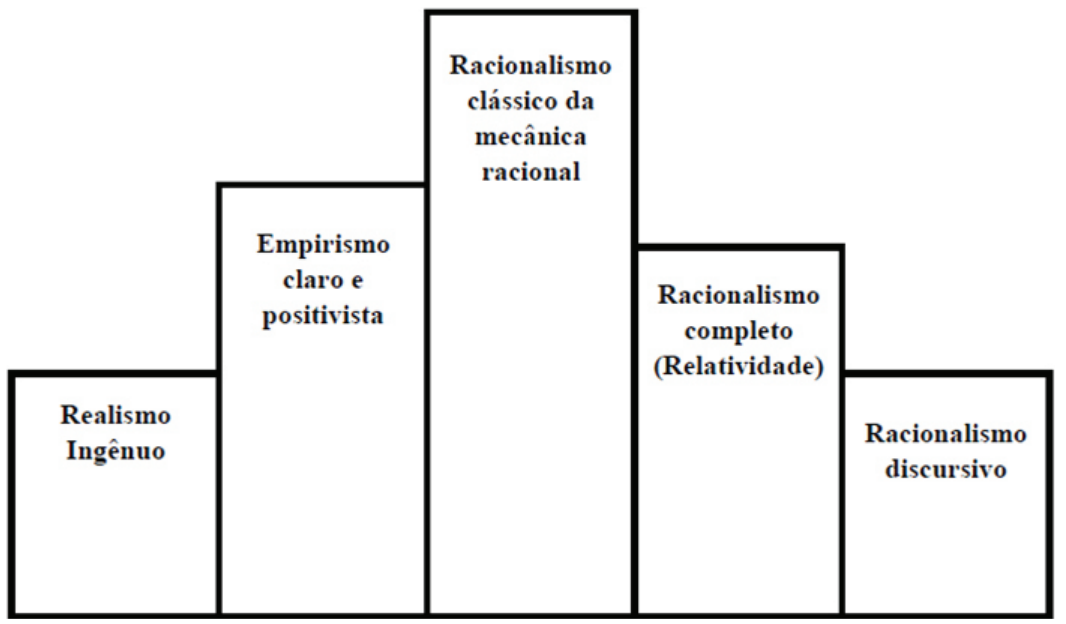

Figura 1. Perfil epistemológico referente à noção de massa de Bachelard (Bachelard, 1978, p.25, adaptada) 
É importante destacar que este perfil epistemológico é de um conceito específico, massa, e de um espírito particular inserido em um contexto particular. Logo, o perfil pode ser diferente de espírito para espírito, seja de uma pessoa para outra, ou a mesma em um momento de maior ou menor desenvolvimento do seu espírito científico.

Observamos o quão intenso é o Racionalismo Clássico para a noção de massa de Bachelard. Ele atribui esse fato ao ensino escolar de Física que apresenta essa disciplina relacionada a uma matemática clássica que valoriza esse tipo de racionalismo. Segundo Bachelard (1978), essa é "[...] uma prova de como as filosofias mais sãs, como o racionalismo newtoniano e kantiano, podem em determinadas circunstâncias, constituir um obstáculo ao progresso da cultura" (p.26). Deve-se sempre manter o espírito científico vigilante. A noção de massa além do Racionalismo Clássico existe para Bachelard (1978), mas necessita de esforço para ser alcançada.

Bachelard (1978) também justifica a grande importância da noção empirista de massa que aparece em seu perfil devido ao seu trabalho com Química e com a pesagem de cartas na administração dos Correios e Telégrafos. Já para explicar a zona realista, Bachelard (1978) afirma que todos possuem suas "horas de realismo" para esse conceito, pois “[...] não nos psicanalisamos inteiramente" (p.26).

Alguns trabalhos como Souza Filho (2009) e Martins (2004) tratam do perfil epistemológico bachelardiano. O primeiro mostra os resultados do curso Fundamentos Históricos do Eletromagnetismo, que teve como público 15 alunos do segundo ou terceiro ano do curso de licenciatura em Física da Unesp de Bauru/SP. O curso foi estruturado seguindo o método de psicanálise bachelardiano: conscientização; desequilibração e familiarização. Com o auxílio de textos históricos, a etapa da familiarização desenvolveu a abstração dos alunos. Os autores verificaram que os alunos não possuíam o realismo ingênuo tão acentuado para os conceitos do eletromagnetismo, os perfis epistemológicos se concentraram mais no empirismo e no racionalismo.

O segundo trabalho, Martins (2004), utilizou entrevistas semiestruturadas com alunos do ensino fundamental e dividiu as respostas em duas categorias: como os alunos percebem a passagem do tempo e como eles o medem e aspectos ontológicos sobre a natureza do tempo dos alunos. Segundo o autor, a adoção do referencial bachelardiano, em específico, dos obstáculos e perfis epistemológicos, foi satisfatória, contudo, aconteceram algumas limitações, por exemplo, a impossibilidade de se traçar o real perfil epistemológico dos alunos devido a dificuldade de se fornecer todos os contextos para usarem o conceito.

Baseados em alguns trabalhos como os citados nos parágrafos anteriores e no conceito de perfil epistemológico bachelardiano, nós pesquisamos quais eram os perfis epistemológicos de alguns livros didáticos de Física, aprovados no PNLD 2018, para o conceito de força. Certamente, as considerações sobre o perfil epistemológico de um livro devem ser cautelosas, uma vez que tal conceito é estabelecido para o indivíduo. Dessa forma, consideramos que os perfis dos autores estão refletidos naqueles que são explicitados pelos livros. 
Os resultados dessa pesquisa servem como um alerta aos professores que utilizam os livros didáticos de Física como um referencial teórico para explicarem o conceito de força. Se não é possível, em curto prazo, modificar os livros didáticos, faz-se necessário que os professores se posicionem de modo crítico frente a eles, não os considerando como uma partitura que deve ser seguida à risca.

\section{PROCEDIMENTOS METODOLÓGICOS}

Pesquisamos, no Centro de Aplicação Pedagógica da Universidade Estadual de Maringá (CAP/UEM), quais livros didáticos de Física, aprovados pelo PNLD de 2018, estão disponíveis em sua biblioteca. Encontramos as 12 coleções aprovadas ${ }^{1}$, então optamos por aqueles que foram escolhidos pelos professores dos colégios estaduais de Maringá como primeira ou segunda opção². Apenas os livros que apresentam o conteúdo de Mecânica, em geral, o primeiro volume das coleções, fizeram parte de nossa amostra, pois é onde o conceito de força é trabalhado mais detalhadamente. A Figura 2 apresenta, em ordem alfabética, a lista dos livros selecionados para a análise.

\begin{tabular}{|c|}
\hline Livros Analisados \\
\hline BARRETO e XAVIER. Física aula por aula: mecânica, $1^{\circ}$ ano - 3. Ed. São Paulo: FTD, 2016. \\
\hline BONJORNO et al. Física: Mecânica, 1ª ano. - 3. Ed. São Paulo: FTD, 2016. \\
\hline DOCA et al. Física: mecânica: ensino médio, volume 1 - 3. Ed. São Paulo: Saraiva, 2016. \\
\hline FILHO e TOSCANO. Física: Interação e tecnologia, volume 1 - 2 Ed. São Paulo: Leya, 2016. \\
\hline GUIMARÃES et al. Física: Mecânica, $1^{\circ}$ ano - 2. Ed. São Paulo: Ática, 2016. \\
\hline MÁXIMO et al. Física: contexto e aplicações, $1^{\circ}$ ano - 2. Ed. São Paulo: Scipione, 2016. \\
\hline
\end{tabular}

Figura 2. Livros selecionados para a análise

Para nos auxiliar na organização e análise dos dados obtidos, seguimos o percurso heurístico sugerido pela Análise de Conteúdo (Bardin, 1977). Primeiramente, após uma leitura flutuante, identificamos os trechos que continham a palavra "força", ou as que os próprios livros definiam como força, tais como: "peso" e "tração". Excluímos as áreas destinadas aos exercícios, pois não tinham explicações mais elaboradas sobre esse conceito. Na sequência, verificamos em quais contextos as palavras destacadas estavam inseridas, classificando o perfil epistemológico daquela situação. Por exemplo, se a palavra força estava associada à figura de uma pessoa empurrando algo, ela foi classificada no perfil Realista, pois apresentava a concepção de força como esforço muscular.

\footnotetext{
${ }^{1}$ As coleções podem ser encontradas no seguinte site: http://www.fnde.gov.br/pnld-2018/.

${ }^{2}$ A relação dos livros escolhidos pode ser encontrada no site http://pddeinterativo.mec.gov.br/, selecionando o quadro de resultado de escolha das obras e discriminando o estado do Paraná, a Cidade de Maringá e o tipo da esfera da escola como Estadual.
} 


\section{CARACTERIZAÇÃO DAS REPRESENTAÇÕES DE FORÇA AO LONGO DA HISTÓRIA}

De acordo com Jammer (2011), a concepção de força ao longo da história da ciência sofreu inúmeras modificações, sendo compreendida de diversos modos, tais como: originada da percepção motora, indistinta de energia, trabalho, potência, poder e movimento; antropomórfica; animista; de origem divina; reguladora do universo; natural; 'simpatia' (atração dos semelhantes); força impressa (de contato); inerente ao objeto, agindo a distância; resistência ao movimento do objeto como força (vis resistiva); força como sequência de impulsos instantâneos que se somam; força centrípeta e centrífuga, como reguladora do movimento circular dos corpos; conceito apriorístico, intuitivo; força como um dado, valor; força como um vetor, podendo ser decomposta segundo a regra do paralelogramo; aspecto dual agindo em pares de ação e reação, possivelmente a distância; derivada do momento com relação ao tempo; análoga à força newtoniana, porém, com a massa relativística; até a possibilidade de não se tratar efeitos mecânicos como a ação de forças para a consideração de uma propriedade do espaço-tempo. Entre essas concepções, identificamos e categorizamos quatro perfis epistemológicos: Realismo Ingênuo, Empirismo Claro e Positivista, Racionalismo Clássico e Racionalismo Completo (ou complexo).

- Realismo Ingênuo: inclui as situações em que a força é: associada com o esforço humano; compreendida como simpatia entre os iguais, em que agia por meio de uma rede que interligava tudo em meio a atração dos iguais e repulsão dos diferentes; relacionada como uma característica, um "poder" de uma entidade sobre-humana capaz de determinar o destino da humanidade; compreendida como uma substância fluida diferente de toda a matéria, chamada de "mente", ou um agente regulador externo da natureza; considerada como o motor do movimento. Além disso, também se enquadra nesse perfil os casos em que a própria matéria é entendida como composta de uma essência dita espiritual que representa a força original, ou entendendo que ela é um organismo vivo e existe para regular e equilibrar a natureza.

- Empirismo claro e positivista: está muito presente na noção do ímpetus medieval. Para refutar a teoria de Aristóteles, que possuía inúmeros adeptos, Jean Buridan, no século XIV, construiu uma teoria que relacionava, qualitativamente, a velocidade com a quantidade de matéria, permitindo, desse modo, distinguir o ímpeto recebido por cada corpo.

- Racionalismo clássico: é o perfil em que se enquadra a noção de força newtoniana, que se torna quantitativa, cuja expressão matemática é construída posteriormente por Leonhard Euler (1707 - 1783).

- Racionalismo Completo (ou complexo): nesse perfil temos a força interpretada por Mach, Kirchhoff e Hertz, no final do século XIX, como algo puramente matemático e não mais um evento físico real. As causas foram substituídas por uma análise pura da cinemática do sistema. A descrição do fenômeno em termos matemáticos assume o protagonismo. 
A ausência do perfil Racionalista Dialético se justifica por atualmente a mecânica quântica e a física nuclear estudarem propostas diversificadas de interações sem reconstruírem um novo conceito que supere o perfil anterior de força mecânica. Consideramos a Teoria da Relatividade Especial e a Teoria da Relatividade Geral como estando na transição entre os perfis Racionalismo Completo (ou complexo) e o Racionalista Dialético. Apesar do conceito de força, na primeira teoria, não ser radicalmente modificado - há apenas uma modificação na equação da mecânica clássica devido à nova concepção de espaço-tempo - , ela rompe com a simultaneidade absoluta dos eventos, tornando impossível fisicamente a ação a distância. Em complemento, a segunda teoria considera a gravitação como uma propriedade do espaço-tempo, não mais como uma força, e flexibiliza o princípio da ação e reação (Jammer, 2011).

Portanto, consideramos que tais teorias não se enquadram no escopo de nossa pesquisa. Contudo, concordamos que a ciência não é estática e ainda há muito trabalho a ser desenvolvido pela Relatividade e a Quântica. Desse modo, o caminho está aberto para o surgimento, na Física, do perfil Racionalista Dialético para o conceito de força.

\section{PERFIL EPISTEMOLÓGICO DOS LIVROS}

O primeiro livro, Barreto e Xavier (2016), apresentou uma quantidade menor da palavra "força". Há muitas seções de textos contendo história da ciência e algumas aplicações ou, ainda, indicações de filmes para introduzir os conceitos que serão apresentados no corpo do capítulo. Das 886 palavras "força” presentes no livro, 25 eram de títulos, subtítulos e outros tipos de conotação não físicas, 258 estavam nos exercícios. Restaram apenas 603 palavras para a análise. Somando-se as 77 palavras que o livro define como força - peso, tração, empuxo e normal -, analisamos 680 palavras. No total, classificamos: 252 palavras no perfil Realista; 304 no Racionalista Clássico e 124 no Racionalista completo. A Figura 3 mostra um gráfico de barras desses perfis.

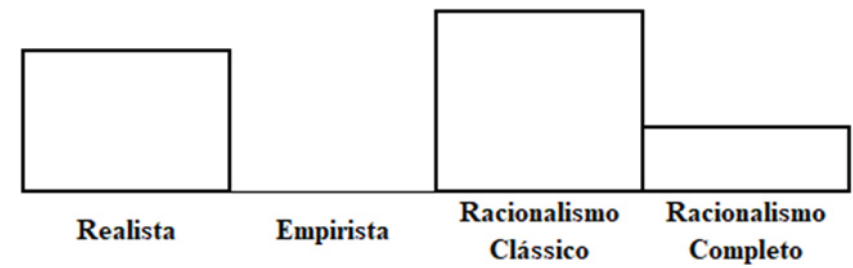

Figura 3. Perfil epistemológico do livro Barreto e Xavier (2016) sobre o conceito de força

Logo, na maioria das vezes, a palavra "força" está relacionada à uma equação ou identificada por meio de vetor (Racionalismo Clássico). Foram poucos os casos em que ela foi considerada apenas como uma ferramenta matemática (Racionalismo Completo). Além disso, foram feitas diversas associações entre força e esforço físico (Realista). 
Para o segundo livro analisado, Bonjorno et al. (2016), encontramos 722 palavras "força". Descartamos as 251 que apareceram em títulos, subtítulos e fora do contexto científico. Somando-se as 54 palavras que o livro define como força - peso, tração, empuxo e normal -, analisamos 525 palavras. No total, classificamos: 129 palavras no perfil Realista; 2 no Empirista; 316 no Racionalista Clássico e 78 no Racionalista Completo. A Figura 4 mostra um gráfico de barras desses perfis.

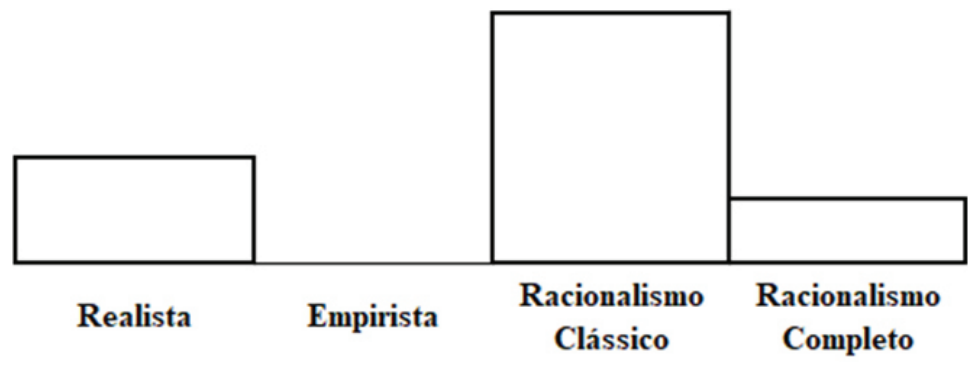

Figura 4. Perfil epistemológico do livro Bonjorno et al. (2016) sobre o conceito de força

O gráfico é muito similar ao encontrado no livro anterior e são as mesmas as explicações que justificam cada barra.

No terceiro livro, Doca et al. (2016), foram encontradas 860 palavras "força". Desprezamos 135, pelos mesmos motivos anteriores. Somando-se as 128 palavras que o livro define como força - peso, tração, empuxo e normal -, analisamos 853 palavras. No total, classificamos: 294 palavras no perfil Realista; 437 no Racionalista Clássico e 122 no Racionalista Completo. A Figura 5 mostra um gráfico de barras desses perfis.

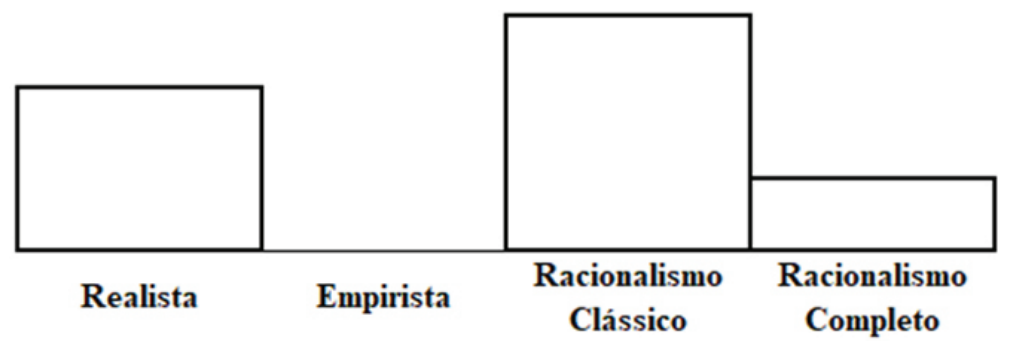

Figura 5. Perfil epistemológico do livro Doca et al. (2016) sobre o conceito de força

Em relação à porcentagem de cada perfil, esse livro está no meio-termo dos dois anteriores.

Para o quarto livro, Filho e Toscano (2016), encontramos 1142 palavras “força”. Não consideramos 33 que eram de títulos, subtítulos ou estavam incluídas em situações que não eram do interesse da pesquisa, bem como, 428 que apareciam nos exercícios. Desse 
modo, restaram 681, somadas com 72 que o próprio livro definiu como força, totalizaram 753 palavras analisadas. No total, classificamos: 193 palavras no perfil Realista; 445 no Racionalista Clássico e 115 no Racionalista Completo. A Figura 6 mostra um gráfico de barras desses perfis.

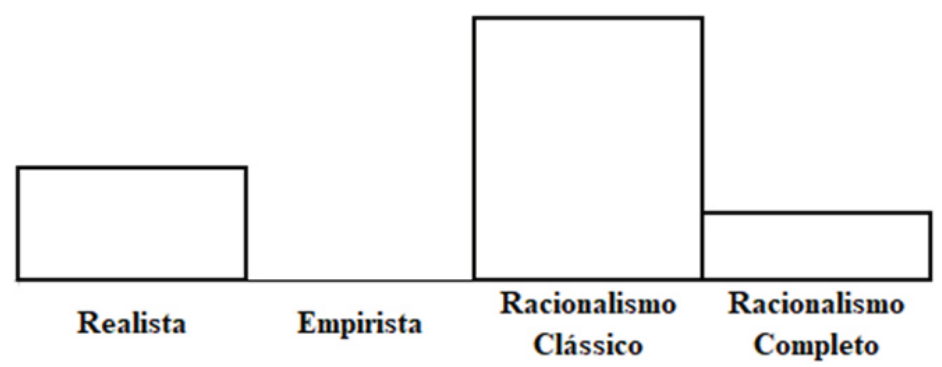

Figura 6. Perfil epistemológico do livro Filho e Toscano (2016) sobre o conceito de força

No quinto livro, Guimarães et al. (2016), contabilizamos 834 palavras "força", desconsiderando 196 que apareciam em exercícios, títulos e subtítulos das seções, ou estavam fora do contexto científico, restaram 638. Somadas com 79 que foram definidas como força, totalizaram 717 palavras analisadas. No total, classificamos: 127 palavras no perfil Realista; 6 no Empirista; 507 no Racionalista Clássico e 77 no Racionalista Completo. A Figura 7 mostra um gráfico de barras desses perfis.

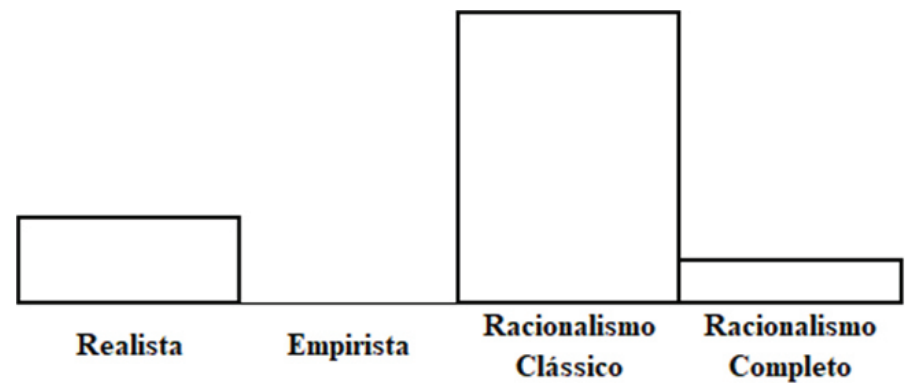

Figura 7. Perfil epistemológico do livro Guimarães et al. (2016) sobre o conceito de força

Este livro foi o que apresentou a maior diferença entre os perfis, com destaque para o perfil Racionalismo Clássico. Na obra aparece uma intensa utilização da força como representação vetorial e expressões matemáticas. Salientamos, ainda, que apesar de haver poucas expressões associando força com esforço físico, ainda se fez presente o perfil Realista.

Para o sexto livro, Máximo et al. (2016), encontramos 1003 palavras "força". Subtraindo 240 que estavam presentes em exercícios, títulos, subtítulos e outras situações 
alheias ao tema da pesquisa, restaram 763 palavras. Somando-se as 202 palavras que o livro define como força - peso, tração, empuxo e normal -, analisamos 965 palavras. No total, classificamos: 398 palavras no perfil Realista; 461 no Racionalista Clássico e 106 no Racionalista completo. A Figura 8 mostra um gráfico de barras desses perfis.

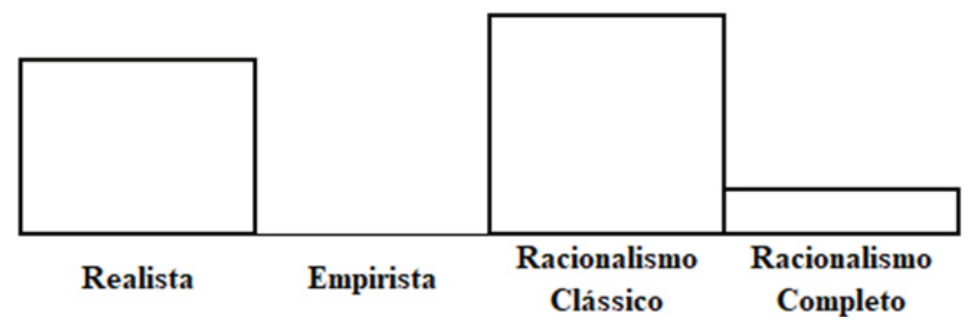

Figura 8. Perfil epistemológico do livro Máximo et al. (2016) sobre o conceito de força

\section{RESULTADOS E DISCUSSÕES}

Todos os livros tiveram o perfil Racionalismo Clássico elevado em comparação com os demais. Tal característica revela que, na maioria das vezes, no Ensino Médio, o conceito de força é apresentado na transição entre o concreto (Empirista) e o abstrato (Racionalismo Completo).

Pela análise verificamos que o perfil Realista ainda está muito presente nesse nível de ensino. Ele aparece nos livros como uma forma cômoda de conceituação do conceito de força e prejudica uma compreensão mais próxima da aceita atualmente pela ciência. Há um excessivo número de figuras e frases que associam a força mecânica ao esforço muscular, assim como há muitas atribuições animistas aos objetos inanimados, principalmente, por meio das expressões "puxando" e "empurrando". Os livros Máximo et al. (2016) e Barreto e Xavier (2016) foram os que apresentaram com maior intensidade esse perfil.

No livro Bonjorno et al. (2016), encontramos uma subseção intitulada "Força", em que há uma tentativa de se explicar e/ou definir o conceito. Assim, são apresentadas três imagens de pessoas fazendo atividades físicas, seguidas do seguinte trecho: "Nos exemplos podemos observar que a grandeza física chamada força, de forma intuitiva, pode ser considerada com um 'empurrão' ou um 'puxão' correspondendo a uma força de ação de um corpo sobre o outro" (p.122).

Era de se esperar que tal afirmação fosse apenas uma introdução ao assunto, uma maneira de se partir do concreto até se chegar no abstrato. Porém, ao longo do livro, não há um desenvolvimento do conceito. Isso dificulta o entendimento das duas imagens que são mostradas na página seguinte do trecho citado, ilustrando o conceito de forças a distância (Figura 9). Nelas, sem maiores explicações, a força gravitacional é apresentada por meio de uma pessoa pulando e a força magnética por meio de objetos metálicos presos a um imã. Ou seja, novamente trocam-se as reflexões mais racionalistas (abstratas) do conceito por aquilo que é observável, empírico (concreto). 

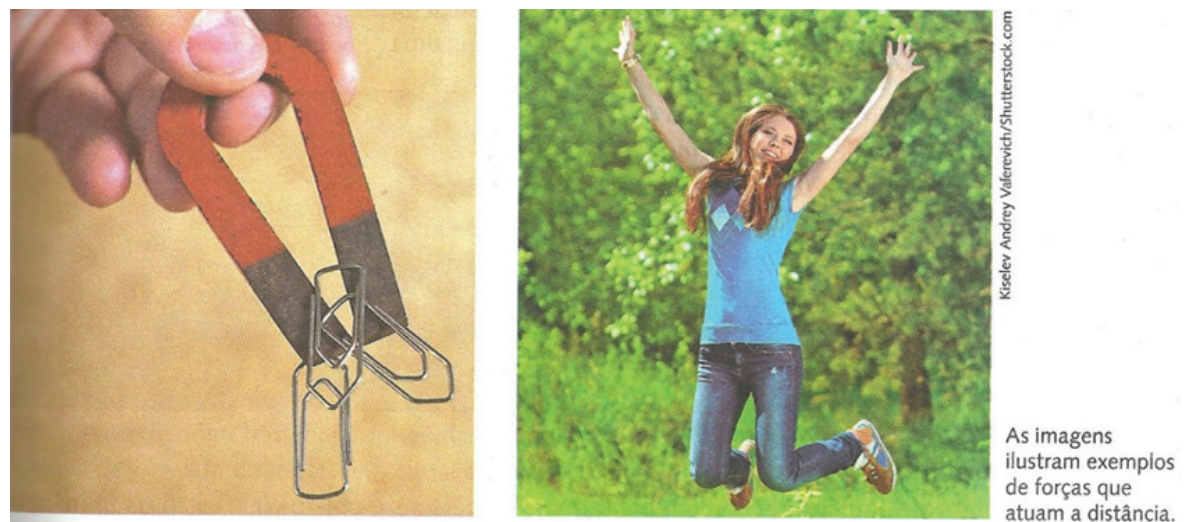

Figura 9. Imagens que ilustram forças a distância (Bonjorno et al., 2016, p.123)

As Figuras 10 e 11 exemplificam a identificação do perfil Realista em todos os livros analisados.

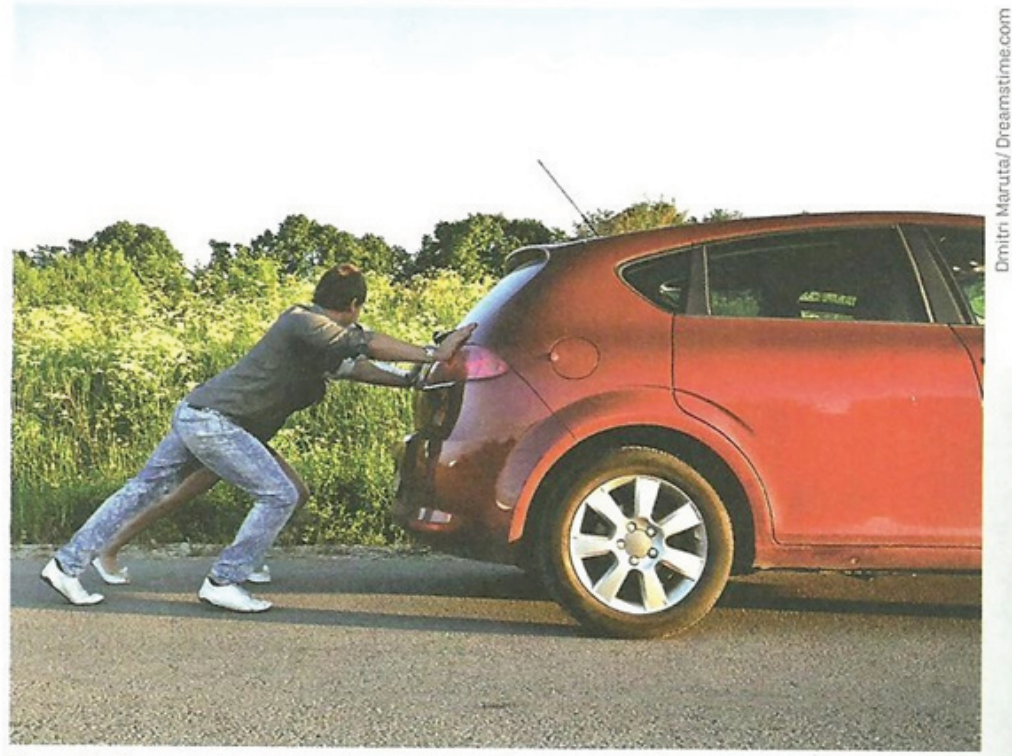

Figura 3: Pessoas empurrando um carro. A força média feita por elas deve ser aplicada durante um grande intervalo de tempo para que o veículo seja colocado em movimento.

Figura 10. Imagem de pessoas utilizando do esforço físico para empurrar o carro (Filho \& Toscano, 2016, p.40) 

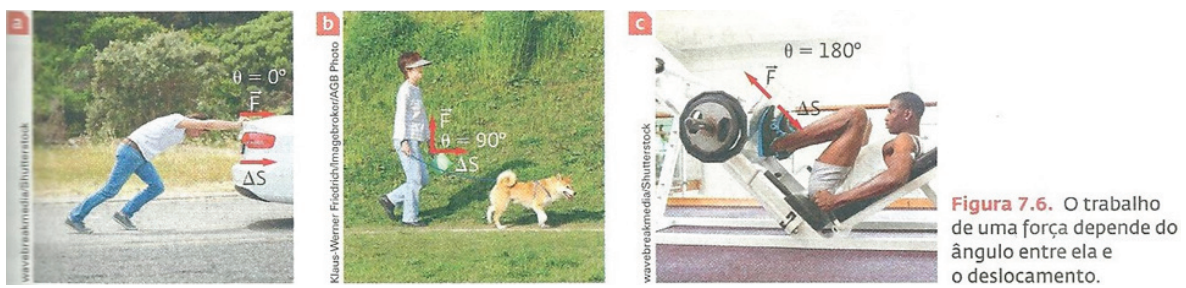

Figura 11. Imagens de pessoas realizando trabalho em diversos ângulos entre a força e o deslocamento (Máximo et al., 2016, p.177)

Ao tratar do conteúdo de alavancas, o livro Máximo et al. (2016) se enquadra no perfil Realista ao apresentar o conceito de força associado ao esforço muscular, como segue:

O braço humano tem estrutura semelhante a uma alavanca interpotente. A mão que segura algum peso exerce o papel da força resistente, a força aplicada pelo músculo em um osso do antebraço é a força potente, e a junção no cotovelo é o ponto de apoio (p.279)

O trecho seguinte do livro Doca et al. (2016) foi categorizado no perfil Realista por associar a palavra força aos fenômenos naturais, ficando implícita a noção de natureza viva que contém um poder oculto: "Constituem, com os terremotos, uma força natural de imenso poder destruidor. Na maior parte dos casos, no hemisfério Sul os ciclones tropicais têm rotação horária ocorrendo o oposto no hemisfério Norte" (p.80).

Por outro lado, o perfil Empirista praticamente não apareceu, menos de $1 \%$ das vezes o conceito de força se enquadrou nesse perfil. Talvez pelo fato da força, diferente da massa, não ser uma característica intrínseca de um corpo. Desse modo, ela escapa de uma apreciação imediata pelos sentidos.

Não encontramos a noção clara de impetus, mas há momentos sutis que se referem à força como alguma substância capaz de ser transportada de um lugar para outro, ou até mesmo podendo ser trocada entre dois objetos por meio do contato e/ou colisão. Contudo, a força não era consumida ao longo do movimento, como afirmava a teoria de Buridan.

A representação da Força por meio de vetores é um procedimento característico do perfil Racionalismo Clássico, pois está associada a uma análise matemática mais sofisticada, como mostra a Figura 12. 


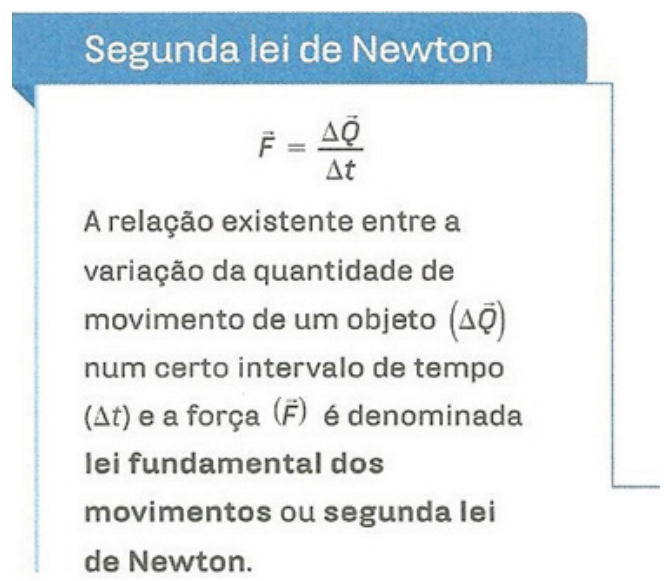

Figura 12. Imagem que contém a conceituação da Segunda lei de Newton em uma expressão matemática seguida de um texto explicativo (Filho \& Toscano 2016, p.45).

Os dois trechos a seguir também servem como representantes dos demais que foram classificados nesse perfil:

Podemos usar a segunda lei de Newton para estudar a queda livre de um objeto: a força gravitacional, ou peso $(\vec{P})$, corresponde ao produto entre a massa $(m)$ do objeto e a aceleração da gravidade $\left(\vec{a}_{g}\right)$ (Filho \& Toscano, 2016, p.51)

[...] a força $\vec{F}$ pode ser decomposta na componente normal (perpendicular à superfície - força normal $\vec{N}$ ) e na componente tangencial (paralela à superfície força de atrito $\left.\vec{F}_{a t}\right)$ [...]. (Barreto \& Xavier, 2016, p.128, grifo do autor)

É importante destacar que, em muitos casos, mesmo trabalhando com a expressão matemática ou a representação vetorial, o texto manifesta o perfil Realista e Racionalista Clássico, pois a força é representada como um ente físico real que causa a variação do movimento. Desse modo, a busca por uma compreensão mais abstrata do conceito perde a sua motivação.

\section{CONSIDERAÇÕES FINAIS}

A intensa utilização de metáforas pelos livros reflete a quantidade alta de Realismo encontrada. Apesar de se esperar que tal perfil já tivesse sido superado nesse nível de ensino. Há um uso excessivo de imagens e trechos que associam o conceito de força ao esforço muscular. Mesmo quando há a utilização de vetores, o agente ou o motor do 
movimento está no ser humano ou em animais, reforçando a ideia de que somente seres vivos são capazes de exercerem força, o que prejudica uma compreensão mais ampla do conceito de ação e reação.

Os livros deveriam problematizar mais o conceito de força objetivando construir reflexões mais abstratas sobre o mesmo. Em termos de racionalismo bachelardiano, isso facilitaria a superação dos obstáculos epistemológicos e o desenvolvimento de perfis epistemológicos mais complexos.

\section{REFERÊNCIAS}

Bachelard, G. (1978). A filosofia do não (Coleção Os Pensadores). São Paulo, SP: Abril Cultural.

Barreto, B., \& Xavier, C. (2016). Física aula por aula: mecânica: Vol. 1 (3ª ed., Coleção física aula por aula). São Paulo, SP: FTD.

Bardin, L. (1997). Análise de conteúdo (L. A. Reta \& A. P. Capa, Trans.). Lisboa, Portugal: Edições 70. (Obra original publicada em 1977).

Bonjorno, J. R., Ramos, C. M., Prado, E.P., Bonjorno, V., Bonjorno, M. A., Casemiro, R., \& Bonjorno, R. F. S. A. (2016). Física: Mecânica: Vol. 1 (3 ${ }^{\mathrm{a}}$ ed., Coleção Física). São Paulo, SP: FTD.

Doca, R. H., Biscoula, G. J., \& Bôas, N. V. (2016). Física: mecânica: Vol. 1 (3 ed.). São Paulo, SP: Saraiva.

Filho, A. G., \& Toscano, C. (2016). Física: Interação e tecnologia: Vol. 1 (2 $2^{\mathrm{a}}$ ed.). São Paulo, SP: Leya.

Guimarães, O., Piqueira, J. R., \& Carron, W. (2016). Física: Mecânica (2a ed., Coleção Física: Ensino Médio). São Paulo, SP: Ática.

Jammer, M. (2011). Conceitos de força: estudo sobre os fundamentos da dinâmica. (V. Ribeiro \& A. Mattoso, Trans.). Rio de Janeiro: Contraponto: Ed. PUC-Rio. (Obra original publicada em 1957).

Martins, A. F. P. (2004). Concepções de estudantes acerca do conceito de tempo: uma análise à luz da epistemologia de Gaston Bachelard (218f.). Tese de doutorado, Faculdade de Educação da Universidade Estadual de São Paulo, São Paulo.

Máximo, A., Alvarenga, B., \& Guimarães, C. (2016). Física: contextos e aplicações: Vol. 1 ( $2^{\mathrm{a}}$ ed.). São Paulo, SP: Scipione.

Souza Filho, M. P. (2009) O erro em sala de aula: subsídios para o Ensino do eletromagnetismo (230f.). Tese de doutorado, Faculdade de Ciências da Unesp, Bauru- SP. 